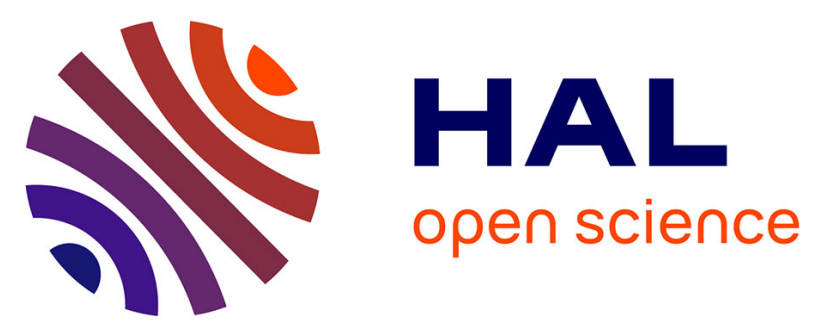

\title{
Breakaway characterization of Zircaloy-4 oxidized in steam and in oxygen at high temperatures using HT- $\mathrm{XRD}$ analysis
}

\author{
Roland Zino, Raphaël Chosson, Maelig Ollivier, Eric Serris
}

\section{To cite this version:}

Roland Zino, Raphaël Chosson, Maelig Ollivier, Eric Serris. Breakaway characterization of Zircaloy-4 oxidized in steam and in oxygen at high temperatures using HT- XRD analysis. Corrosion Science, 2020, 176, pp.109028. 10.1016/j.corsci.2020.109028 . emse-02961012

HAL Id: emse-02961012

https://hal-emse.ccsd.cnrs.fr/emse-02961012

Submitted on 12 Oct 2020

HAL is a multi-disciplinary open access archive for the deposit and dissemination of scientific research documents, whether they are published or not. The documents may come from teaching and research institutions in France or abroad, or from public or private research centers.
L'archive ouverte pluridisciplinaire HAL, est destinée au dépôt et à la diffusion de documents scientifiques de niveau recherche, publiés ou non, émanant des établissements d'enseignement et de recherche français ou étrangers, des laboratoires publics ou privés. 


\title{
Breakaway characterization of Zircaloy- 4 oxidized in steam and in oxygen at high temperatures using HT- XRD analysis
}

\author{
Roland ZINO ${ }^{(1,2)}$, Raphaël CHOSSON ${ }^{(2)}$, Maelig OLLIVIER ${ }^{(1)}$, Eric SERRIS ${ }^{(1)}$ \\ (1) Mines Saint-Etienne, Univ Lyon, CNRS, UMR 5307 LGF, Centre SPIN, F - 42023 Saint-Etienne \\ France
}

(2) Framatome, 69456 Lyon France

\section{Key words}

Zircaloy-4, breakaway, thermogravimetric analysis, HT-XRD, steam, HT corrosion

\section{Introduction}

Zirconium alloys are widely used as the main structural material for fuel cladding tubes in Pressurized Water Reactors (PWR). Safety demonstrations include the study of postulated accidents, such as LossOf-Coolant Accidents (LOCA). In such scenarios, the fuel rods could be oxidized in steam at high temperature, up to $1200^{\circ} \mathrm{C}$ before the core reflooding [1, 2]. $\mathrm{ZrO}_{2}$ forms on the cladding surface while a fraction of oxygen diffuses in the metal, leading to the formation of an oxygen stabilized $\alpha-\operatorname{Zr}(0)$ metallic phase. In these conditions, breakaway oxidation could occur, as reported in the literature [311], enhancing the cladding oxidation. Breakaway oxidation is defined by an acceleration of the oxidation kinetics accompanied by possible hydrogen pick-up and oxide spallation.

Breakaway oxidation of zirconium alloys has been studied since the 1950s [12]. However, today the mechanisms at the root of this behavior are still unclear. One of the main possible explanations proposed in the literature is the tetragonal-to-monoclinic phase transition of zirconia [8,13-16]. Other explanations found in the literature are the stress relaxation in the oxide when it reaches a critical thickness $[13,17]$ and the evolution of the oxide morphology during oxidation leading to the formation of a short circuit of oxygen via micro-pores $[18,19]$.

The martensitic transformation of $\mathrm{ZrO}_{2}$ from tetragonal to monoclinic phase involves a $4.5 \%$ volume expansion and a $9^{\circ}$ shear [20] and could trigger crack formation according to Yoo et al. [21]. Based on the $\mathrm{Zr}-\mathrm{O}$ binary phase diagram, the monoclinic and the tetragonal zirconia phases are stable at thermodynamic equilibrium respectively below and above $1170^{\circ} \mathrm{C}$ [22]. The tetragonal phase is observed at lower temperatures [23, 24] being stabilized by high internal stresses within the oxide, small oxide grain size or high concentration of charge defects [25-27]. These conditions are met near the oxide/metal interface, where inward growth oxidation occurs and where tetragonal zirconia is preferentially formed, whereas the monoclinic phase predominates moving towards the oxide/gas interface. This was recently highlighted by Guillou et al. using in-situ Synchrotron X-ray diffraction analyses on Zy-4 samples oxidized under oxygen and helium mixtures at 700,800 and $900{ }^{\circ} \mathrm{C}$ [28].

Breakaway oxidation is easily evidenced but the underlying mechanisms are difficult to identify for several reasons. First, the breakaway phenomenon is very sensitive to the specimen history, i.e. its manufacturing process, the cleaning protocol and the experimental apparatus used for oxidation [29, 30]. For example, previous studies have shown that two cladding tubes having the same chemical composition but different manufacturing processes exhibit different oxidation behaviors in terms of breakaway resistance [29]. Another reason is the fact that cooling down to room temperature implies an irreversible microstructure change. In other words, the post-mortem structural observations are not representative of the high temperature state making difficult the interpretation of room temperature examinations [31, 32]. These changes are due to phase transformations, thermal expansion and the stress relief occurring in each of the three layers (monoclinic $\mathrm{ZrO}_{2}, \alpha-\operatorname{Zr}(\mathrm{O})$ and $\beta$ $\mathrm{Zr}$ ). This could explain the contradictory results found by Kim et al. [6], where in-situ XRD analyses were performed on oxidized samples reheated to the previous oxidation temperature. In fact, the authors saw no variation in the tetragonal phase fraction at different temperatures, whereas it should be increasing with temperature according to the binary phase diagram, as shown by Gosset et al. [32]. 
This illustrates the importance of in-situ characterization when studying the breakaway phenomenon and the necessity of a cautious analysis of the post-test examinations after cooling to room temperature.

Considering the transition of zirconia from tetragonal to monoclinic phase as a possible cause of breakaway, High Temperature X-Ray Diffraction (HT-XRD) analyses in steam conditions showing the evolution of these phases with time was never achieved before, to the best of our knowledge.

In this frame, the breakaway phenomenon on Zy-4 samples has been characterized using two in-situ methods, thermogravimetric analysis and HT-XRD analyses in steam and oxygen atmospheres. The purpose was to better understand the breakaway phenomenon and to verify some unclear hypotheses proposed in the literature. First, isothermal oxidation in steam atmosphere in thermobalance allowed the verification of the occurrence of breakaway phenomenon as reported in the literature. Secondly, HT-XRD analyses in steam and oxygen atmospheres made possible the evaluation of the relationship between breakaway oxidation and zirconia phase transformations, providing a real time tracking of the zirconia phase fraction at the oxide surface during oxidation.

\section{Materials and methods}

The test material is as-received stress-relieved Zircaloy-4 provided by Framatome. The standard chemical composition of the samples is shown in Table 1 . The samples used are $5 \times 5 \times 0.425 \mathrm{~mm}^{3}$ sheets for both thermogravimetric and HT-XRD analyses. All the specimens were cleaned for $5 \mathrm{~min}$ in acetone followed by $5 \mathrm{~min}$ in ethanol using an ultrasonic cleaner and then air-dried.

\begin{tabular}{llllll}
\hline $\begin{array}{l}\text { Alloying } \\
\text { element } \\
\text { wt \% }\end{array}$ & Sn & Fe & Cr & 0 & $\mathrm{Zr}$ \\
\hline
\end{tabular}

Table 1 Chemical composition of Zircaloy-4 samples, in wt\%

\subsection{Thermogravimetric analysis}

A TAG-16 SETARAM symmetrical thermobalance allowing continuous recording of the weight gain was used. The sample was suspended using a platinum wire basket in the middle of the furnace in the temperature controlled isothermal zone. A non-reactive alumina sample, having geometry similar to the samples studied, was placed in the reference furnace. The symmetry allows eliminating disturbances associated with the buoyancy force, thus isolating, with 1- $\mu$ g accuracy, the weight gain resulting only from the reaction between the samples and the oxidizing atmosphere.

Seven oxidation temperatures were investigated: $800{ }^{\circ} \mathrm{C}, 880^{\circ} \mathrm{C}, 900{ }^{\circ} \mathrm{C}, 950^{\circ} \mathrm{C}, 1000{ }^{\circ} \mathrm{C}, 1030{ }^{\circ} \mathrm{C}$ and $1100^{\circ} \mathrm{C}$. The earliest breakaway oxidation time for zirconium alloys is generally observed for temperatures around $1000^{\circ} \mathrm{C}$ in the literature $[3,4,6,8,33,34]$. The heating rate was $20^{\circ} \mathrm{C} / \mathrm{min}$ under helium. The cooling rate, from the holding temperature to $400^{\circ} \mathrm{C}$, was about $60^{\circ} \mathrm{C} / \mathrm{min}$ followed by natural cooling to room temperature in helium atmosphere. Once the target temperature was reached, a mixture containing $3 \%$ steam and $97 \%$ helium (with steam partial pressure of $30 \mathrm{hPa}$ ) or $60 \%$ oxygen and $40 \%$ helium was introduced. All the experiments were done at atmospheric pressure and were preceded by furnace purging under primary vacuum. Problems related to steam starvation were avoided, considering the sample dimensions and the total flow rate used for the oxidation tests $[35,36]$.

\subsection{HT-XRD analysis}

In order to characterize the oxide phase's evolution during isothermal oxidation, HT-XRD analyses were performed on Zircaloy- 4 sheet samples. These experiments were conducted in a BRUKER D8 Advance 
diffractometer using $\mathrm{Cu}-\mathrm{K} \alpha$ radiation $(\lambda=1.5406 \AA)$ and mounted in a $\theta / \theta$ configuration: the $\mathrm{X}$-ray tube and the scintillation counter present symmetrical movements while the sample remains horizontal in a fixed central location, thus avoiding material loss during the experiments. The diffractometer was fitted with a HTK16 Anton Paar chamber: a platinum rod allows holding and heating the sample. Prior to each experiment, the system was purged with a continuous flow of pure helium during 16 hours. The heating and cooling rates were respectively $60^{\circ} \mathrm{C} / \mathrm{min}$ and $300^{\circ} \mathrm{C} / \mathrm{min}$ in helium. A mixture of $3 \%$ steam $-97 \%$ helium at a flowrate of $3 \mathrm{l} / \mathrm{h}$ was introduced once the target temperature was reached. The same oxidation temperatures as for the thermogravimetric analysis were tested. These experiments were replicated under a different mixture $\left(60 \% \mathrm{O}_{2}-40 \% \mathrm{He}\right)$ in order to check the potential influence of the oxidizing atmosphere.

For this study, the range of interest is $26^{\circ}<2 \theta<39^{\circ}$, where the theoretical intensities of the main phases of the zirconium oxide and metal are found (see Table 2). The X-ray beam of the HT-XRD apparatus allows scanning the totality of the upper sample surface.

\begin{tabular}{llll}
\hline & (hkl) & $2 \theta$ & $\mathrm{l} / \mathrm{Imax}(\%)$ \\
\hline $\mathrm{ZrO}_{2} \mathrm{M}$ & $(\mathrm{I} 11)$ & 28.2 & 100 \\
(Monoclinic & $(111)$ & 31.5 & 68 \\
zirconia) & $(002)$ & 33.9 & 21 \\
& $(020)$ & 34.7 & 13 \\
& $(200)$ & 35.4 & 15 \\
$\mathrm{ZrO}_{2} \mathrm{~T}$ & $(101)$ & 30.1 & 100 \\
(Tetragonal & $(002)$ & 34.5 & 9 \\
zirconia) & $(110)$ & 35.1 & 12 \\
$\alpha-\mathrm{Zr}$ & $(100)$ & 32.0 & 24 \\
& $(002)$ & 34.9 & 25 \\
& $(101)$ & 36.1 & 100 \\
$\beta-\mathrm{Zr}$ & $(110)$ & 35.8 & 100 \\
\hline
\end{tabular}

Table 2 The theoretical intensities of zirconia and zirconium phases in the corresponding $2 \theta$ diffraction range [31]

The samples were oxidized for $10550 \mathrm{~s}$ during which 7 scans were performed under oxidizing atmosphere for $650 \mathrm{~s}$ every $1000 \mathrm{~s}$ from $\mathrm{t}=0 \mathrm{~s}$ marking the beginning of the isothermal conditions. In addition, the samples were analyzed during the cooling phase at two temperatures, $800^{\circ} \mathrm{C}$ and $400{ }^{\circ} \mathrm{C}$ and finally a last scan was performed at room temperature. Figure 1 sums up the protocol used in this study. 


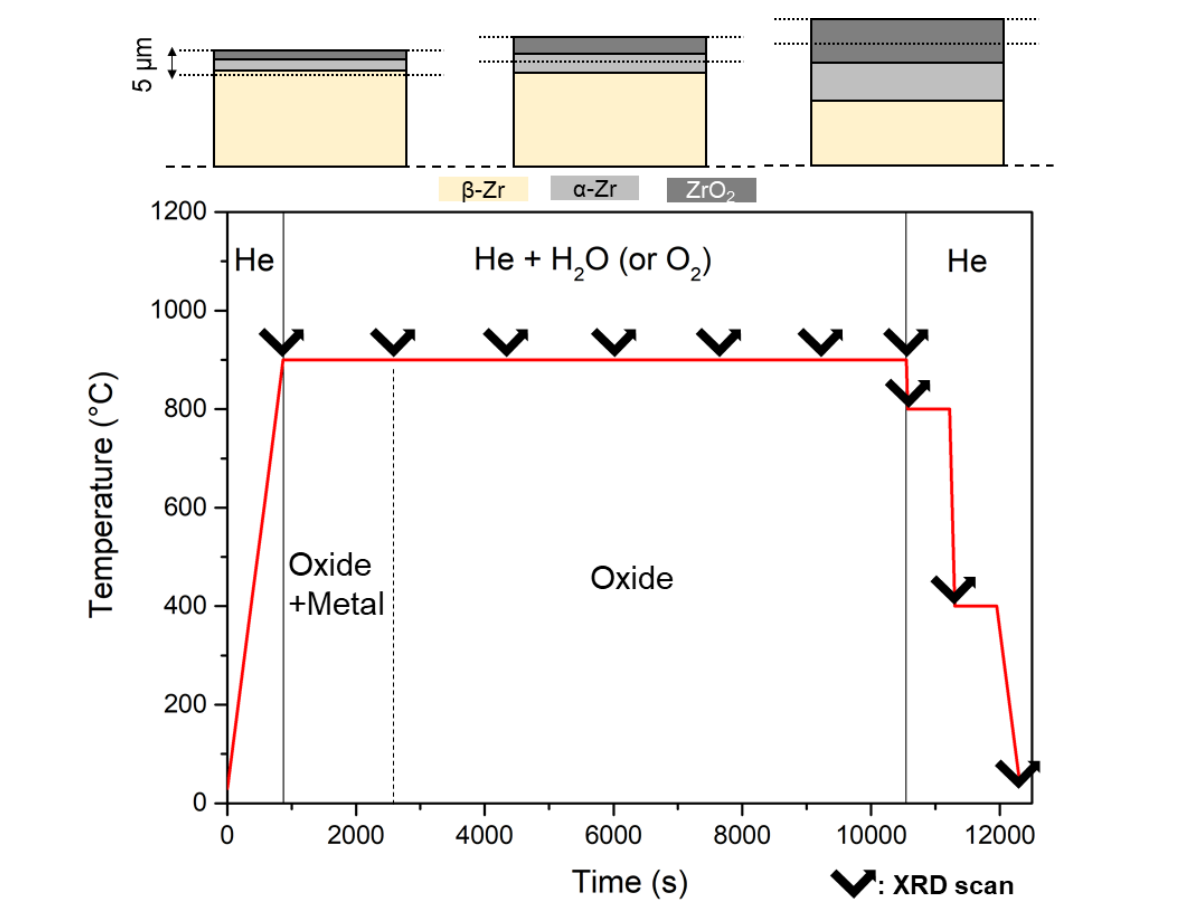

Figure 1 Protocol used for the HT-XRD experiments. Only the first 5 um are analyzed.

Sample heating was achieved by heat conduction from the platinum plate. This implied a temperature gradient through the thickness from the sample surface in contact with the heated plate to the analyzed surface exposed to the oxidizing environment ( $\left.T_{\text {set point }}>T_{\text {analyzed surface }}\right)$ mainly caused by the radiation effect. In order to characterize this gradient, qualification tests were performed beforehand, with a type-S thermocouple (Pt-10\%RhPt) placed in contact with the exposed surface as shown in Figure 2. An average temperature difference of $140{ }^{\circ} \mathrm{C}$ ( $\left.T_{\text {analyzed surface }}-T_{\text {set point }}\right)$ was measured between the analyzed surface and the heated lower surface. Based on this characterization of the thermal gradient, the control temperatures for the HT-XRD tests were set in order to obtain the same temperature at the oxidized surface of the sample as those achieved in the thermogravimetry campaign.

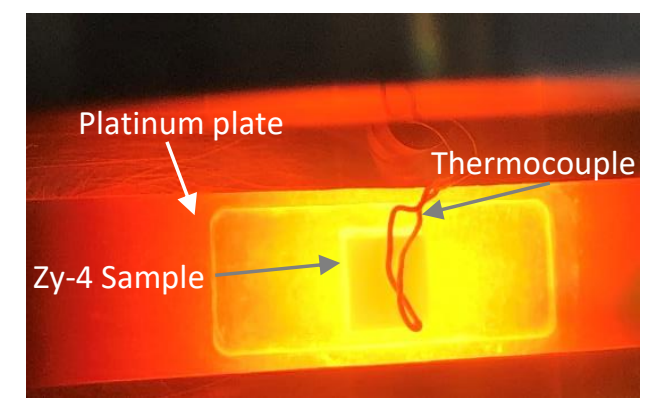

Figure 2 Image of the heated sample and the thermocouple in the HT-XRD apparatus when measuring the temperature gradient through the sample thickness

If it is assumed that breakaway is the consequence of tetragonal to monoclinic zirconia as proposed in the literature, a local transition to breakaway oxidation should be associated with a phase transformation in the oxide, detectable on the diffraction diagrams. 


\section{Results and discussion}

\subsection{Thermogravimetric analysis}

Figure 3 displays the oxidation curves for $\mathrm{Zy}-4$ at 7 different temperatures from $800{ }^{\circ} \mathrm{C}$ to $1100{ }^{\circ} \mathrm{C}$ in a mixture of $3 \%$ steam $-97 \%$ He. The weight gain rate curves in Figure 3 (b) and (c) show a quick acceleration of the oxidation rate in the first seconds of the experiment, resulting from the sudden oxidation of the bare metal when the oxidizing mixture was introduced. The increase in the reaction rates marks the nucleation of the newly formed oxide at the surface of the metal. Once a homogeneous protective oxide layer covers the whole sample, the oxidation rate progressively decreases with time.

The total mass gain kinetics obtained for all the temperatures except at $1000^{\circ} \mathrm{C}$ and $1030{ }^{\circ} \mathrm{C}$ follows a monotonic cubic (for $\mathrm{T}<1000^{\circ} \mathrm{C}$ ) or parabolic behavior (for $\mathrm{T}>1000^{\circ} \mathrm{C}$ ) in accordance with the literature $[9,15,33,37,38]$. At $1000^{\circ} \mathrm{C}$, the kinetic curves show the onset of breakaway oxidation: the weight gain kinetics change from a quasi-parabolic curve to a linear one. The transition time, defined in this study as the local minimum of the weight gain rate curves (Figure 3 (b)) just before the acceleration, is about $1500 \mathrm{~s}$. Using the same method on the curves depicted in Figure 3 (c), the weight gain at the transition time is found to be close to $7.2 \mathrm{mg} / \mathrm{cm}^{2}$. At $1030{ }^{\circ} \mathrm{C}$, the transition to breakaway oxidation occurred after $6700 \mathrm{~s}\left(24 \mathrm{mg} / \mathrm{cm}^{2}\right)$.

- $\frac{\Delta m}{S}$ : Weight gain/surface-area in $\mathrm{mg} / \mathrm{cm}^{2}$

- $\frac{d(\mathrm{~m} / \mathrm{S})}{d t}$ : Weight gain rate/surface-area in $\mathrm{mg} / \mathrm{cm}^{2} / \mathrm{min}$ 


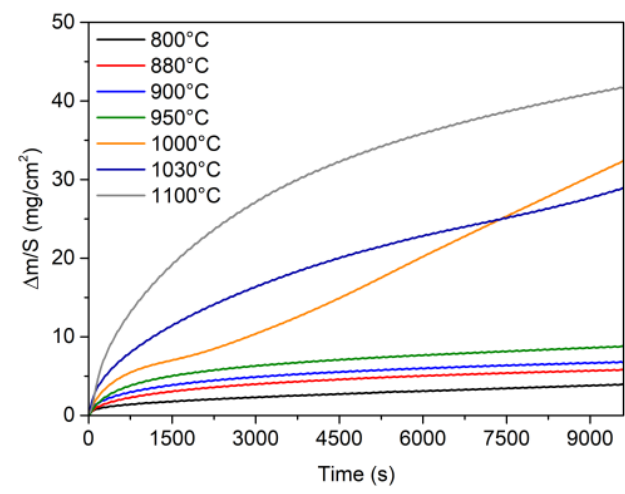

(a)

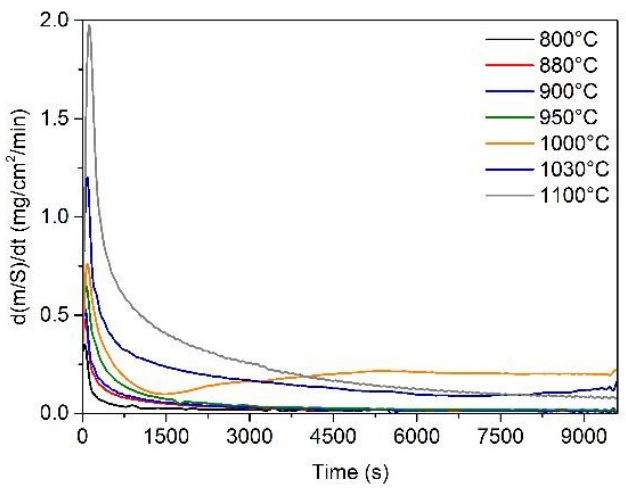

(b)

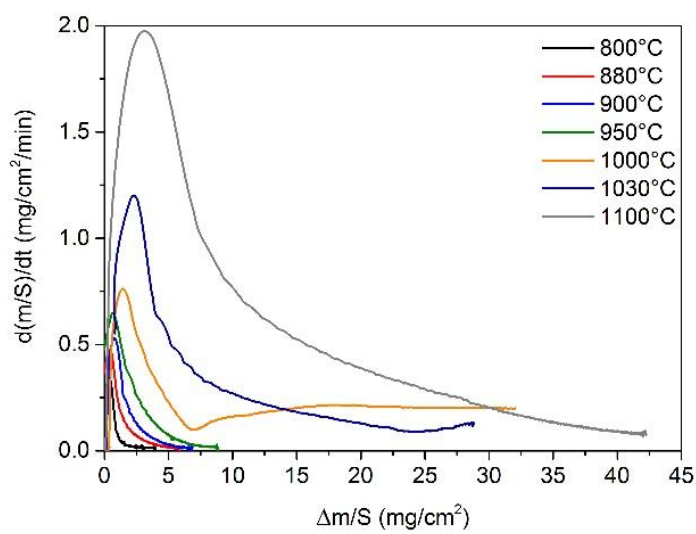

(c)

Figure 3 Kinetic curves for $\mathrm{Zy}-4$ oxidized at different temperatures in $3 \% \mathrm{H}_{2} \mathrm{O}-97 \% \mathrm{He}$ (a) weight gain (b) weight gain rate as a function of time and (c) weight gain rate as a function of weight gain

The earliest breakaway time is obtained at $1000{ }^{\circ} \mathrm{C}$ in accordance with the literature $[8,15,33]$. The difference between the results obtained in this study and the literature regarding the effective transition time could result from the experimental protocols and from the methods used to estimate these parameters.

Figure 4 shows the optical micrographs of three oxidized samples at 900,1000 and $1100{ }^{\circ} \mathrm{C}$ in $3 \% \mathrm{H}_{2} \mathrm{O}$ - $97 \% \mathrm{He}$ for $10000 \mathrm{~s}$. The oxides formed at 900 and $1100^{\circ} \mathrm{C}$ are dense and adherent to the metal substrate, whereas the oxide formed at $1000^{\circ} \mathrm{C}$ shows circumferential cracks resulting from the breakaway oxidation.

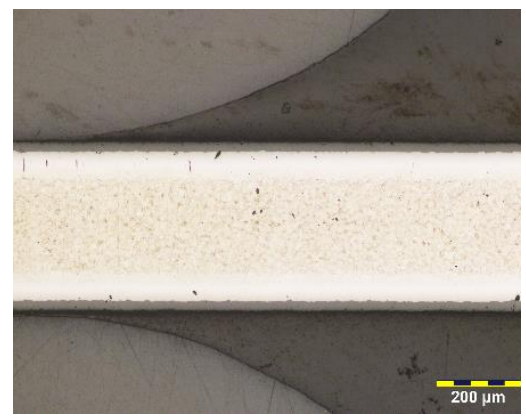

(a) $900^{\circ} \mathrm{C}$

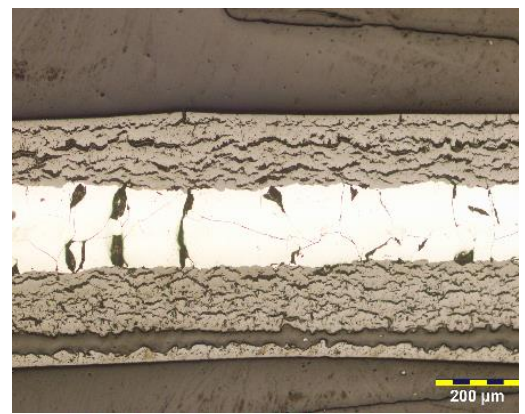

(b) $1000^{\circ} \mathrm{C}$

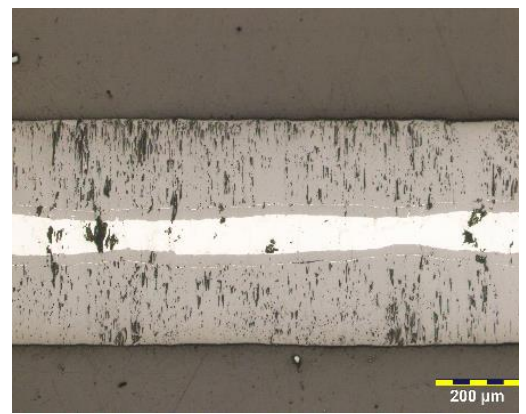

(c) $1100^{\circ} \mathrm{C}$

Figure 4 Optical micrographs of Zircaloy-4 oxidized in $3 \% \mathrm{H}_{2} \mathrm{O}-97 \% \mathrm{He}$ at (a) $900{ }^{\circ} \mathrm{C}$, (b) $1000{ }^{\circ} \mathrm{C}$ and (c) $1100^{\circ} \mathrm{C}$. 
Thermogravimetric analyses were also carried out on Zircaloy-4 samples at $900,1000,1030$ and $1100^{\circ} \mathrm{C}$ under a mixture of $60 \% \mathrm{O}_{2}-40 \% \mathrm{He}$ in order to verify if breakaway oxidation occurs at 1000 and $1030^{\circ} \mathrm{C}$ as reported in the literature [44]. Indeed, it can be clearly seen in Figure 5 that a kinetic transition occurred only at $1000{ }^{\circ} \mathrm{C}$ and $1030^{\circ} \mathrm{C}$ after $1400 \mathrm{~s}$ and $4200 \mathrm{~s}$ respectively.

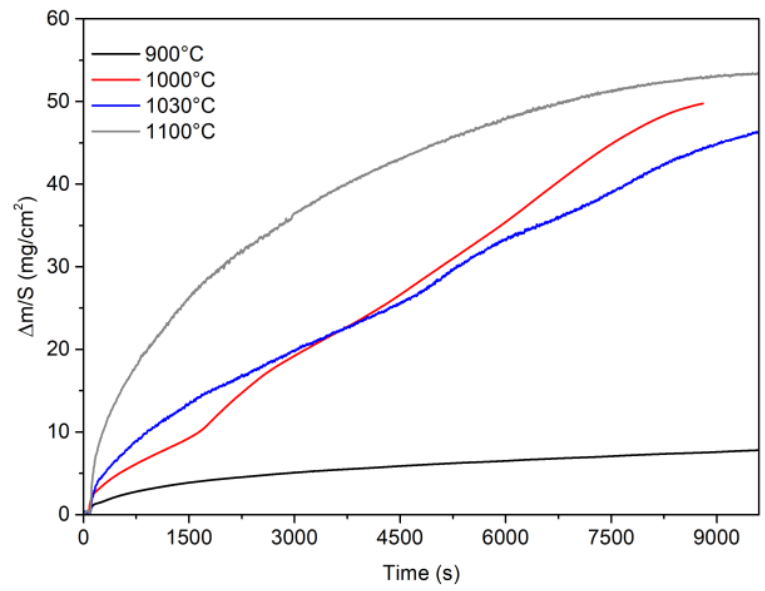

Figure 5 Weight gain curves for Zircaloy-4 oxidized at different temperatures in $60 \% \mathrm{O}_{2}-40 \% \mathrm{He}$.

The results obtained by thermogravimetry confirm that, for the $Z y-4$ sheet samples studied herein, breakaway oxidation occurs at $1000^{\circ} \mathrm{C}$ and $1030^{\circ} \mathrm{C}$ under both atmospheres.

\subsection{HT-XRD analysis}

Figure 6 shows an XRD diagram for a Zy-4 sheet sample after $10 \mathrm{~min}$ of oxidation in steam at $900^{\circ} \mathrm{C}$. The analyzed depth of about $5 \mu \mathrm{m}$ shows monoclinic and tetragonal zirconia peaks. Small peaks corresponding to the metallic substrate are also noticed, this is expected since the oxide thickness formed at the beginning of the isothermal oxidation is lower than $5 \mu \mathrm{m}$. The intensity of the monoclinic peak at $2 \theta=31.5^{\circ}$ is expected to be $68 \%$ of the intensity of the peak at $2 \theta=28.2^{\circ}$ as shown in Table 2. We can clearly see in Figure 6 that this is not the case, which means that the oxide is highly textured.

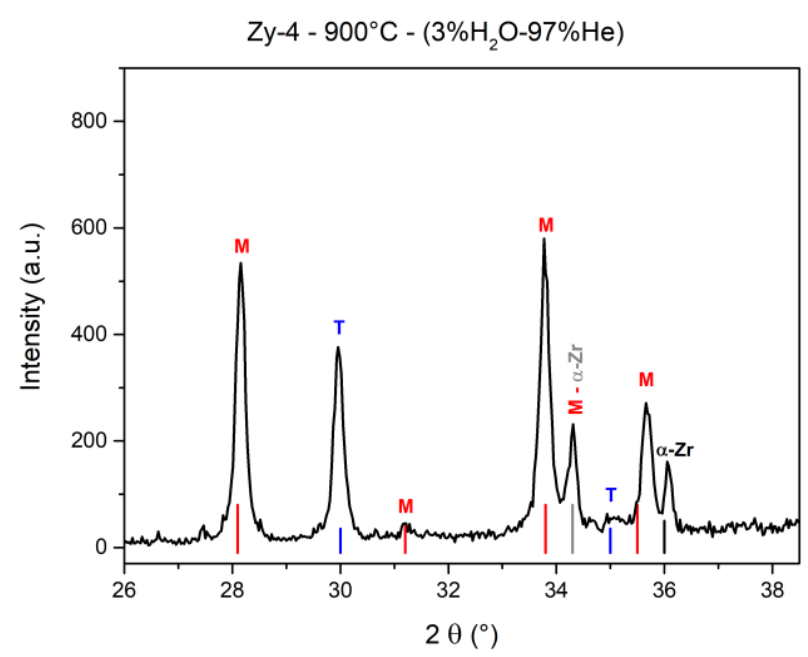

Figure 6 Diffraction diagram of $Z y-4$ during oxidation in steam at $900^{\circ} \mathrm{C}$ (indexation according to [31, 39])

Figure 7 displays the diffraction diagrams obtained at the beginning and at the end of the isothermal oxidation at $1000{ }^{\circ} \mathrm{C}$ in $3 \% \mathrm{H}_{2} \mathrm{O}-97 \% \mathrm{He}$ (at $\mathrm{t}=0 \mathrm{~s}$ and $\mathrm{t}=9900 \mathrm{~s}$ ) as well as the diagrams obtained during the cooling phase at $800^{\circ} \mathrm{C}, 400{ }^{\circ} \mathrm{C}$ and finally at $50^{\circ} \mathrm{C}$. As already established in the literature 
[31, 32], the intensity line at $2 \theta=30.1^{\circ}$, characteristic of the tetragonal zirconia, decreases during the cooling phase and disappears at room temperature. In parallel, a rise in the main monoclinic intensity lines at $2 \theta=28.2$ and $31.5^{\circ}$ is detected. This result confirms that the cooling phase induces a transformation of the tetragonal zirconia to the monoclinic phase, and therefore demonstrates as mentioned in [31] that the state of the Zy-4 samples after cooling to room temperature does not represent what happens during high temperature oxidation.

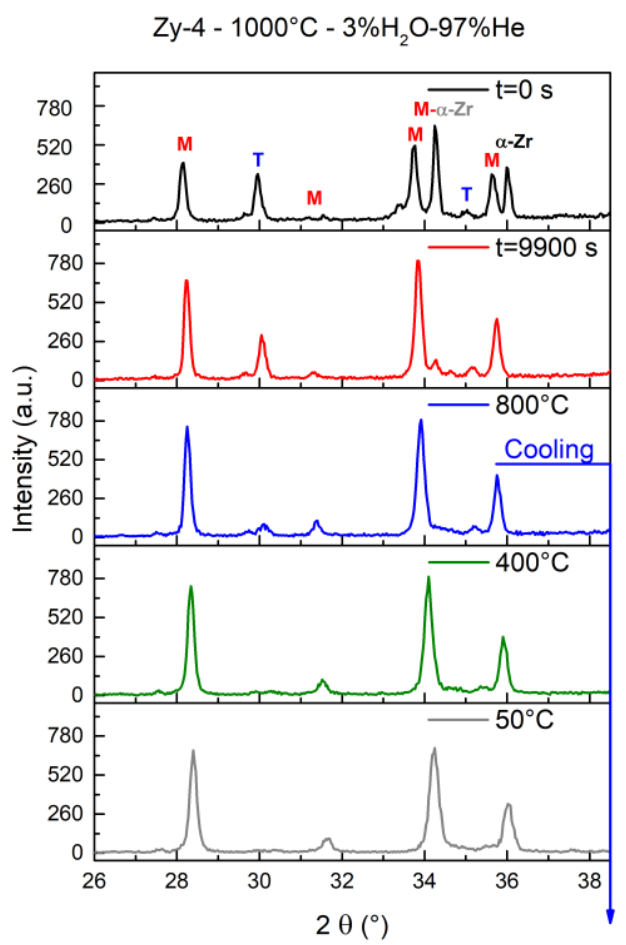

Figure 7 Diffraction diagrams obtained on $Z y-4$ samples during isothermal oxidation at $1000^{\circ} \mathrm{C}$ in steam and during cooling

The oxide formed after oxidation at $1000^{\circ} \mathrm{C}$ for $10550 \mathrm{~s}$ in the HT-XRD apparatus was examined afterwards, to check if breakaway oxidation did occur at this temperature, as expected in the literature and from our results obtained by thermogravimetry. The visual examination of the post-test appearance of the sample in Figure 8 (a) highlights a thicker oxide at the edges. The optical micrograph of the $\mathrm{Zy}-4$ sample oxidized in $3 \% \mathrm{H}_{2} \mathrm{O}-97 \%$ He depicted in Figure 8 (b) reveals crack networks and porosities mainly in the thicker oxide close to the edges of the sample. These observations are characteristics of the breakaway oxidation, starting at the edge of the sample and propagating towards its center.

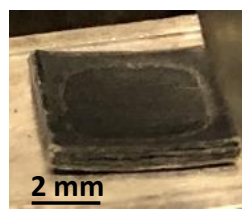

(a)

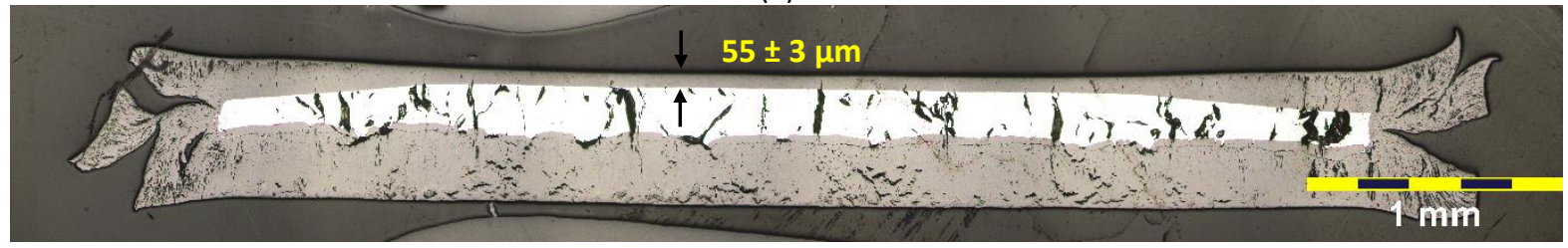

(b)

Figure 8 (a) Photo of a Zy-4 sample at the end of an HT-XRD analysis, oxidized at $1000^{\circ} \mathrm{C}$ in $3 \% \mathrm{H} 2 \mathrm{O}-97 \% \mathrm{He}$ and (b) its corresponding optical micrograph 
Figure 9 shows the diffraction diagrams obtained during isothermal oxidation at $1000{ }^{\circ} \mathrm{C}$ in $3 \% \mathrm{H}_{2} \mathrm{O}-$ $97 \% \mathrm{He}$. The peaks corresponding to both the tetragonal and monoclinic phases remain well defined during the isothermal oxidation. The $\alpha$-Zr intensity line at $2 \theta=36.1^{\circ}$ corresponding to the family of diffraction planes $\{101\}$, appears only in the first scan. This means that starting from the second scan (from $t=1650 \mathrm{~s}$ ) which corresponds to the onset of breakaway oxidation, the $5 \mu \mathrm{m}$ analyzed are located only in the oxide. Indeed, as the oxide grows on the metal, the scanned depth by X-rays (about $5 \mu \mathrm{m}$ beneath the oxide/gas interface) moves progressively away from the oxide/metal interface. This must be kept in mind during the analysis of the results.

Since the goal is to study the evolution of the monoclinic and tetragonal intensity lines during oxidation, we are going to focus on the main diffraction peaks of these two phases located at $2 \theta=28.2^{\circ}$ and $31.5^{\circ}$ for the monoclinic phase and at $2 \theta=30.1^{\circ}$ for the tetragonal phase. For the sample oxidized in steam at $1000^{\circ} \mathrm{C}$, at the beginning of the oxidation, near the oxide metal/interface, the tetragonal main line is maximum and it decreases with time, while the oxide grows and the scanned volume moves away from this oxide/metal interface. The intensities of both monoclinic main lines increase during the first $3300 \mathrm{~s}$ and then stabilize until the end of the experiment. These evolutions indicate a progressive transformation of the tetragonal zirconia phase into monoclinic zirconia in the volume right beneath the external surface of the oxide $(5 \mu \mathrm{m})$.

At $1000{ }^{\circ} \mathrm{C}$, two unidentified peaks appear in the first scan in isothermal conditions at $2 \theta=33.4^{\circ}$ and $38.2^{\circ}$ under both steam and oxygen mixtures. As we can clearly see in Figure 10 those two peaks are present simultaneously (see arrows). The identification of the phase corresponding to these peaks is unclear. A possible candidate phase could be the orthorhombic structure of zirconia which is an unstable intermediate of the tetragonal to monoclinic transition as mentioned by [40]. However, the theoretical peaks corresponding to this phase are inadequate with the diffraction diagrams obtained. Other possibilities are the $\mathrm{ZrO}$ cubic phase having two theoretical peaks at $2 \theta=33.89^{\circ}$ and $39.337^{\circ}$ and the $\mathrm{ZrN}$ cubic phases having also two theoretical peaks at $2 \theta=33.568^{\circ}$ and $38.965^{\circ}$. Since the XRD heating chamber was purged beforehand and the nitrogen impurity was found to be lower than $5 \mathrm{ppm}$ vol., this means that the formation of $\mathrm{ZrN}$ precipitates is quite unlikely. As a result, we can conclude that these peaks most likely correspond to the ZrO cubic phase. Further investigations are necessary to fully confirm the phase characterized by these diffraction peaks. 


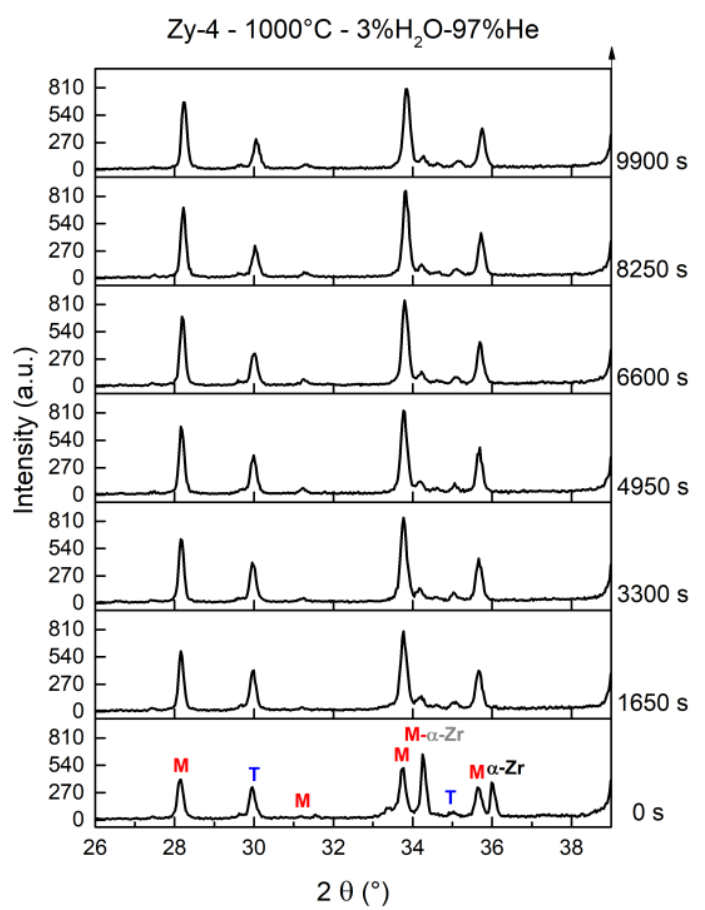

Figure 9 Diffraction diagrams during isothermal oxidation of $\mathrm{Zy}-4$ at $1000{ }^{\circ} \mathrm{C}$ in $3 \% \mathrm{H}_{2} \mathrm{O}-97 \% \mathrm{He}$
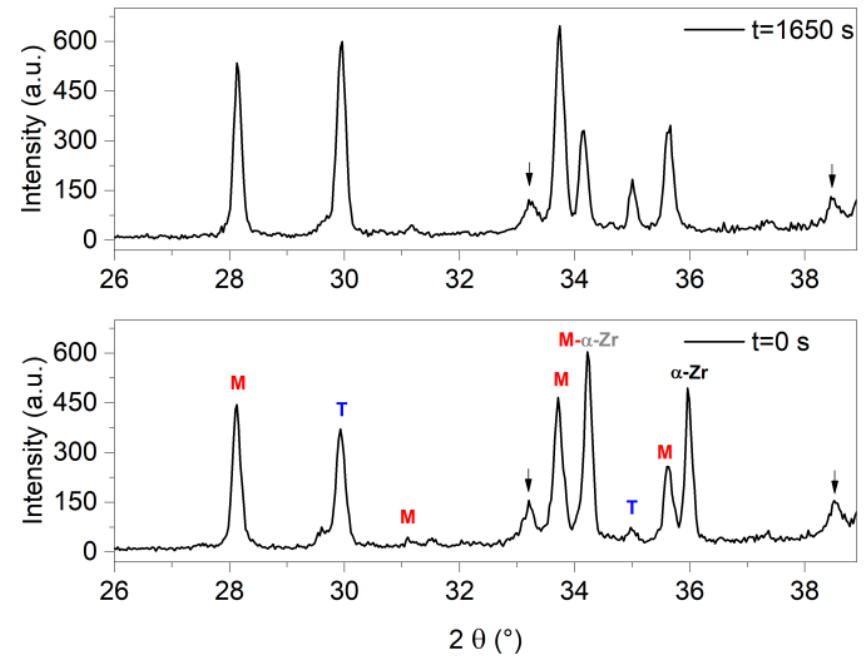

Figure 10 Diffraction diagrams of the first two scans in the isothermal phase at $1000{ }^{\circ} \mathrm{C}$ in $60 \% \mathrm{O}_{2}-40 \% \mathrm{He}$

The diffraction diagrams for the oxidation test at $880^{\circ} \mathrm{C}$ (Figure 11) show a change in the intensity and the position of the monoclinic line at $2 \theta=28^{\circ}$ corresponding to the family of diffraction plans $\{\overline{1} 11\}$ between $1650 \mathrm{~s}$ and $3300 \mathrm{~s}$. This is the result of stress relaxation or a modification of the surface roughness (Figure 11). In fact, oxide spallation was observed on this sample at the end of the experiment. Since this change in the monoclinic line is detected during isothermal oxidation, this probably means that oxide spallation occurred at this point and not during the cooling phase. We can deduce that during HT-XRD analysis, the change in the main monoclinic line at $2 \theta=28^{\circ}$ could be used as an indicator to possible local transitions if they were manifested by oxide spallation. 


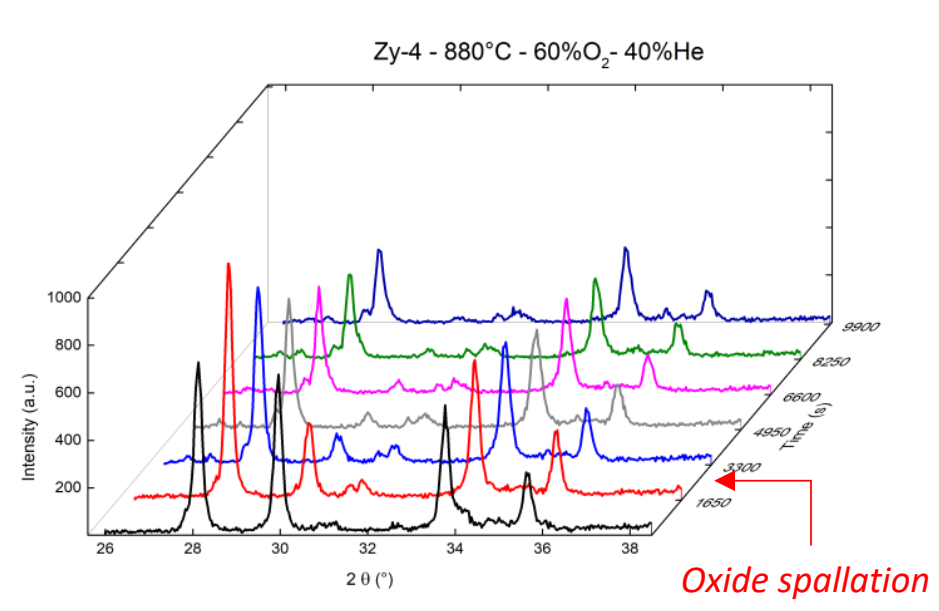

Figure 11 Evolution of the XRD diagrams of $\mathrm{Zy}-4$ oxidized in $60 \% \mathrm{O}_{2}-40 \% \mathrm{He}$ at $880^{\circ} \mathrm{C}$

\subsection{Discussion}

The most commonly used method to determine the tetragonal phase proportion within the oxide is the Garvie-Nicholson method [41], based on the ratio of the intensity of the main lines of the oxide phases:

$$
\frac{T}{T+M} \approx \frac{(101)_{T}}{(101)_{T}+(\overline{1} 11)_{M}+(111)_{M}}
$$

With $T$ being the intensity of the tetragonal phase main line and $M$ the intensities of the monoclinic main lines.

Figure 12 shows the evolution of the tetragonal phase fraction (estimated using equation (1)) in the $5 \mu \mathrm{m}$ of oxide beneath the outer surface, during high temperature oxidation in different atmospheres and at different temperatures. The tetragonal phase fraction does not experience any sudden change with time, even at breakaway times identified by thermogravimetric analysis at $1000^{\circ} \mathrm{C}$ and $1030{ }^{\circ} \mathrm{C}$. Besides, post-test examinations showed that breakaway oxidation did in fact occur on the samples oxidized at $1000{ }^{\circ} \mathrm{C}$ and $1030^{\circ} \mathrm{C}$. These results show that breakaway oxidation is not correlated to a sudden transformation of the tetragonal phase in the oxide, contrary to what was suggested in the literature $[3,21,40,42]$. 


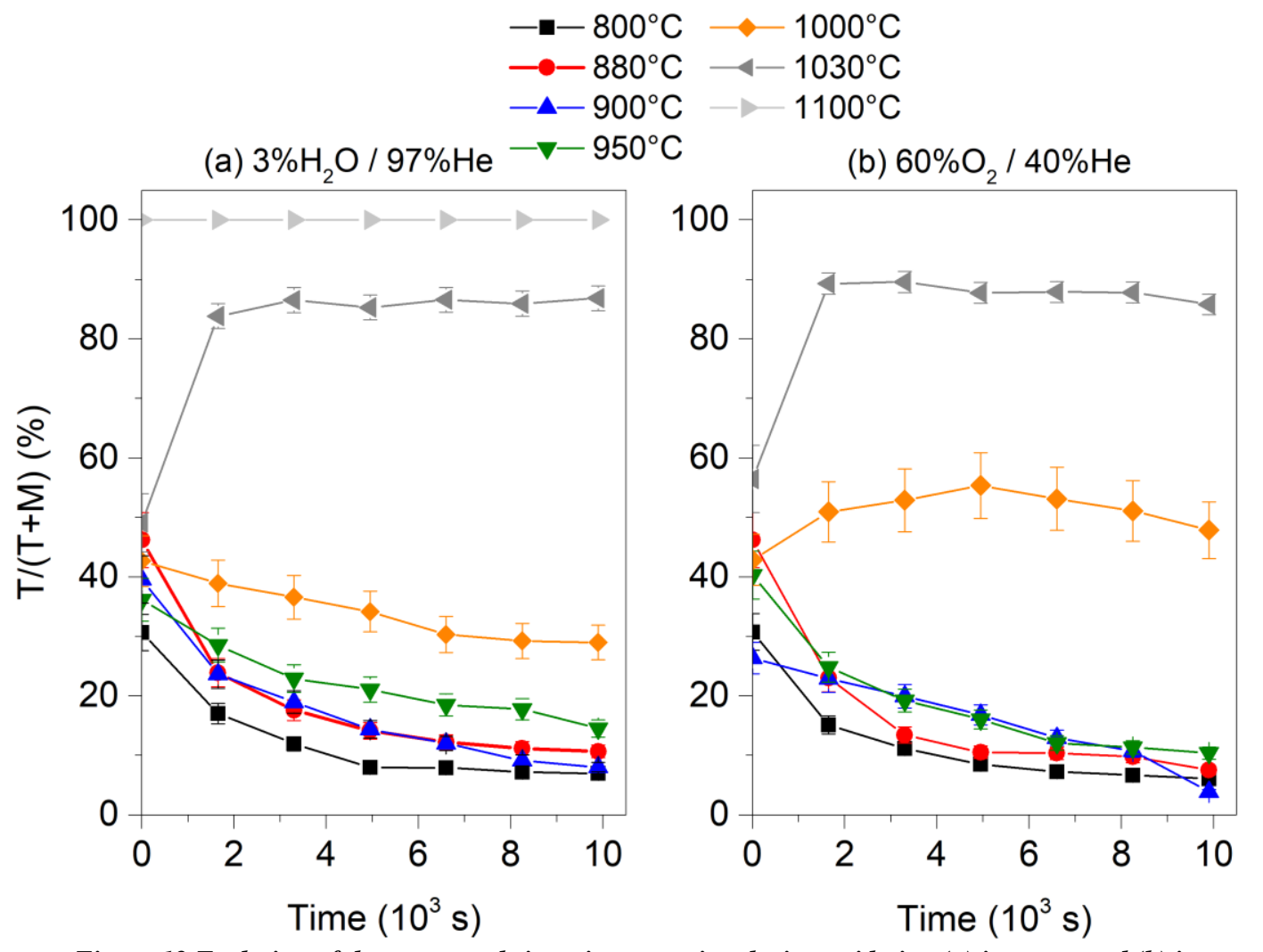

Figure 12 Evolution of the tetragonal zirconia proportion during oxidation (a) in steam and (b) in oxygen

For the temperatures lower than $1000^{\circ} \mathrm{C}$, a similar overall evolution of the tetragonal phase fraction is observed: the fraction is maximum at the beginning of the oxidation (around 35-38\%), near the metal/oxide interface, and decreases with time while the scanned volume moves away from this interface. The remaining tetragonal phase detected at the end of the isothermal oxidation varies from 5 to $14 \%$ for the temperatures below $1000^{\circ} \mathrm{C}$. These results suggest that the tetragonal phase, present in the $5 \mu \mathrm{m}$ beneath the outer surface, transforms partially to monoclinic during oxidation as the scanned volume moves away from the oxide/metal interface.

Table 3 sums up the tetragonal phase fraction in isothermal conditions measured in the $5 \mu \mathrm{m}$ beneath the outer surface. The results are divided in three categories: first, the tetragonal phase proportion after the first scan (close to the metal/oxide interface), second its total variation at the end of the isothermal oxidation. Finally, the tetragonal phase fraction, when the scanned volume is exclusively in the oxide (starting from the second scan to the end of the isothermal oxidation), is calculated.

For the experiments showing a decrease in the tetragonal phase fraction with time, we can notice that this phase remains present in the external oxide layer, with proportions between $5 \%$ and $26 \%$ depending on the oxidation temperature.

Guillou et al. [28] observed the same behavior using Synchrotron X-ray diffraction analyses on Zy-4 sheet samples when scanning the entire oxide thickness formed at $\mathrm{T} \leq 900^{\circ} \mathrm{C}$ in oxygen and helium atmospheres. The authors noticed that the total quantity of the tetragonal oxide, described by its "equivalent" thickness (see ref. [28] for details), remains constant through oxidation. The stabilization of the tetragonal oxide quantity during oxidation time could indicate mainly two scenarios. Either, the tetragonal phase nucleates continuously at the metal/oxide interface and transforms to monoclinic during oxidation in the total volume of the oxide; or, the tetragonal phase is formed only at the very beginning of the reaction in a fixed oxide volume and does not transform into monoclinic with time. 
The decrease in the total tetragonal phase fraction observed by the authors comes from the fact that after a certain time only monoclinic oxide grows.

Since in this study the tetragonal phase fraction near the external oxide surface decreases with oxidation time, and since in [28] the tetragonal phase fraction also decreases in the volume with a constant equivalent thickness, this allows us to conclude that for the temperatures lower than $900{ }^{\circ} \mathrm{C}$, the tetragonal-to-monoclinic transformation occurs in the totality of the oxide volume. At the metal/oxide interface, the tetragonal phase is continuously formed, and the tetragonal-to-monoclinic transformation occurs during oxide growth, moving away from the metal/oxide interface. This clearly demonstrates the importance and benefits of combining the two HT-XRD methods to have a full comprehensive overview of the high temperature oxide phase transformation.

At $1000{ }^{\circ} \mathrm{C}$, different behaviors are observed under each atmosphere. In steam mixture, the tetragonal phase fraction drops from $43 \%$ to $26 \%$ during the isothermal oxidation, whereas in oxygen mixture, a slight increase followed by a stabilization of the tetragonal fraction of about $50 \%$ is observed. Breakaway oxidation occurs at $1000{ }^{\circ} \mathrm{C}$ under both atmospheres. Under steam atmosphere, the kinetic transition could lead to hydrogen pick-up [7]. In this case, hydrogen could destabilize the oxide formed and therefore destabilize the tetragonal zirconia. This hypothesis could explain the decrease of the tetragonal phase fraction observed under steam conditions.

For the sample oxidized at $1100{ }^{\circ} \mathrm{C}$ in steam, only tetragonal oxide was detected during the whole oxidation holding as highlighted by the absence of both main monoclinic lines at $2 \theta=28.2^{\circ}$ and $31.5^{\circ}$. This is in accordance with the literature $[31,32,40]$ and shows that the tetragonal phase is stabilized in the oxide volume close to the outer surface, even after $10550 \mathrm{~s}$.

Finally, at $1030{ }^{\circ} \mathrm{C}$ in steam and oxygen mixtures, the tetragonal phase fraction increases from around $50 \%$ at the first scan to around $90 \%$ at the second one and stabilizes at this value for the rest of the experiment. At $1030^{\circ} \mathrm{C}$, breakaway oxidation was detected in thermogravimetry and in accordance with literature $[8,43,44]$. Post-test examinations of the sample tested in XRD also confirmed occurrence of breakaway oxidation. However, the tetragonal phase fraction remained constant throughout the entire isothermal oxidation, irrespective of the breakaway oxidation occurrence. Therefore, no correlation can be derived between breakaway occurrences and zirconia phase transformation in the scanned volume.

\begin{tabular}{|c|c|c|c|c|c|c|c|c|}
\hline & & & & & & & & \\
\hline & & $800^{\circ} \mathrm{C}$ & $880^{\circ} \mathrm{C}$ & $900^{\circ} \mathrm{C}$ & $950^{\circ} \mathrm{C}$ & $1000^{\circ} \mathrm{C}$ & $1030^{\circ} \mathrm{C}$ & $1100^{\circ} \mathrm{C}$ \\
\hline $60 \% \mathrm{O}_{2}$ & $\begin{array}{l}\text { Proportion at metal/oxide } \\
\text { interface (\%) }\end{array}$ & 30 & 46 & 40 & 26 & 43 & 56 & - \\
\hline- & Total variation* $(\%)$ & -80 & -84 & -74 & -85 & 12 & 52 & - \\
\hline $40 \% \mathrm{He}$ & $\begin{array}{l}\text { Variation in the external } 5 \mu \mathrm{m} \\
\text { oxide*(starting from } 1650 \mathrm{~s})(\%)\end{array}$ & -60 & -67 & -58 & -83 & -6 & -4 & - \\
\hline $3 \% \mathrm{H}_{2} \mathrm{O}$ & $\begin{array}{l}\text { Proportion at metal/oxide } \\
\text { interface (\%) }\end{array}$ & 31 & 46 & 40 & 36 & 43 & 49 & 100 \\
\hline- & Total variation* $(\%)$ & -77 & -77 & -80 & -60 & -32 & 77 & 0 \\
\hline $97 \% \mathrm{He}$ & 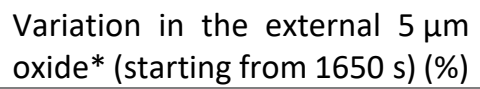 & -59 & -55 & -66 & -49 & -26 & 3 & 0 \\
\hline
\end{tabular}

* The variations in this table are calculated using: $\frac{\text { final value-initial value }}{\text { initial value }}$

Table 3 Evolution of the tetragonal phase fraction for all the tested samples (in \%) in isothermal conditions

For temperatures under the range of existence of tetragonal zirconia at thermodynamic equilibrium $\left(1170^{\circ} \mathrm{C}<\mathrm{T}<2300^{\circ} \mathrm{C}\right)$, the stabilization of this phase can be enhanced by the high-level stresses in the oxide, small oxide grain sizes and charge defects $[25,26]$. In other terms, in the temperature range [950-1050 ${ }^{\circ} \mathrm{C}$ ], tetragonal phase is probably stable mainly at the vicinity of the metal/oxide interface. 
If we consider the hypothesis that breakaway results from the destabilization of the tetragonal phase and its transformation to monoclinic phase, the transformation will most likely initiate at the oxide/gas interface, where the conditions are the most unfavorable to the tetragonal phase stabilization [23].

The TOPAS software from Brucker that takes into account the proper instrumental and correction parameters allowed the evaluation of the size of the coherent diffraction domains (CDD) of each phase at different temperatures. Since it was tricky to provide precise quantitative results, the CDD ratio of both phases (CDD-M / CDD-T) obtained after 1650, 3300 and $4950 \mathrm{~s}$ of isothermal oxidation in both atmospheres is displayed in Figure 13 . The results show that for temperatures lower than $1030{ }^{\circ} \mathrm{C}$ the monoclinic phase presents larger CDD than the tetragonal phase in accordance with the literature [28, 32]. At $1000^{\circ} \mathrm{C}$ the CDD-M is almost twice the size of CDD-T. At $1030^{\circ} \mathrm{C}$ the CDD of the monoclinic and the tetragonal phases are equal in both atmospheres. Since breakaway oxidation appears only at 1000 and $1030^{\circ} \mathrm{C}$ among the studied temperatures, this means that the kinetic transition is probably not directly related to the crystal sizes of both phases.

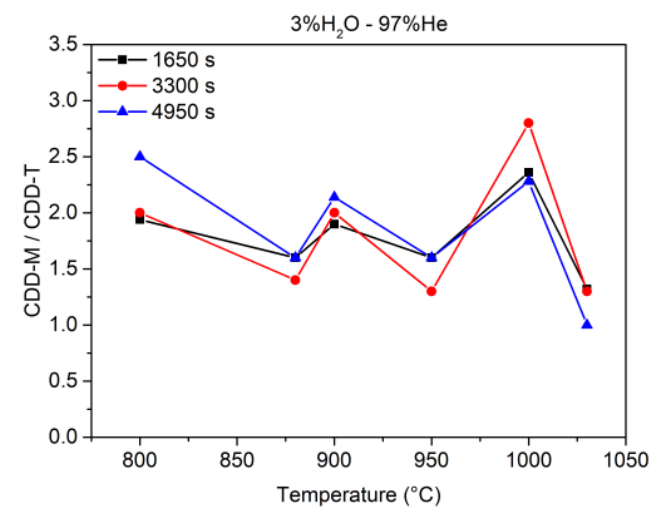

(a)

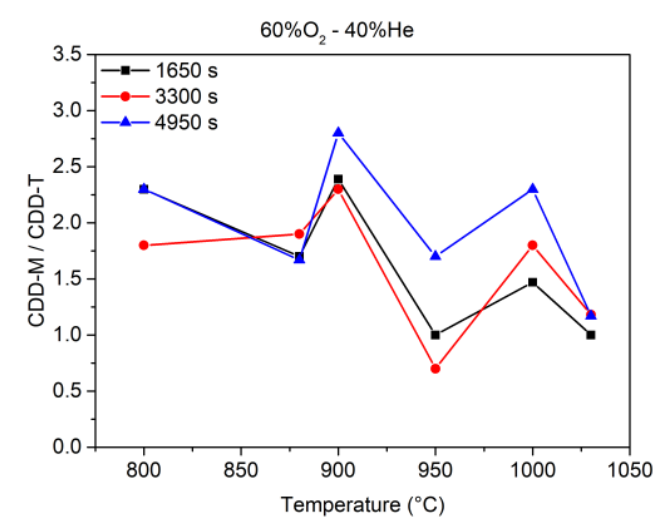

(b)

Figure 13 Ratio of the size of the coherent diffraction domains of tetragonal and monoclinic phases at different temperatures after 1650, 3300 and $4950 s$ of isothermal oxidation in (a) steam and (b) oxygen.

The results of this work show that the zirconia phase transformation cannot be used as an indicator of the occurrence of breakaway, and that this transformation is insufficient to explain the mechanism responsible for the kinetics acceleration of oxidation.

The occurrence of breakaway oxidation seems to be the result of the contribution of different mechanisms intervening simultaneously and causing the failure of the oxide to accommodate to the level of stresses generated within the oxide scale. The stabilization of both the monoclinic and tetragonal phases at temperatures where breakaway occurs could have a contribution on the breakaway phenomenon. This contribution could be explained by the mechanical mismatch and the induced stresses generated when the monoclinic and tetragonal phases coexist in the oxide with comparable quantities and large grains.

\section{Conclusion}

In this study, the high temperature oxidation and breakaway transition were characterized on Zy-4 samples between $800^{\circ} \mathrm{C}$ and $1100^{\circ} \mathrm{C}$ in steam and oxygen mixtures using two in-situ methods: thermogravimetry and HT-XRD. The results of the thermogravimetric analysis validated the occurrence of breakaway in the studied conditions at 1000 and $1030^{\circ} \mathrm{C}$ as observed in the literature. 
HT-XRD analysis showed that a correlation between the breakaway oxidation and the zirconia phase transformation cannot be established. This means that zirconia phase transformation does not explain the mechanism responsible for the kinetic acceleration known as breakaway oxidation.

Nonetheless, the XRD analysis is limited to the oxide volume beneath the outer surface (about $5 \mu \mathrm{m}$ ). Synchrotron HT-XRD analysis could probably enable the study of the phase transformation occurring in a higher analyzed depth in the oxide layer $(>5 \mu \mathrm{m})$, notably at the oxide/metal interface for short oxidation times [28].

However, the tetragonal-to-monoclinic phase transition will most likely initiate from the external surface, where the conditions are the most unfavorable for the tetragonal phase stabilization. This supports the conclusion made in this study, that breakaway oxidation does not result from a sudden tetragonal-to-monoclinic transformation.

The thermogravimetric study will be pursued further to assess the effect of the thermodynamic parameters, i.e. temperature and steam partial pressure, on the high temperature oxidation and breakaway occurrence. The thermogravimetric method will support further understanding of the main causes of breakaway and the proposal of a mechanism that could describe it [45]. 


\section{References}

[1] P. Rudling and R. B. Adamson, '5 - Performance and inspection of zirconium alloy fuel bundle components in light water reactors (LWRs)', in Materials Ageing and Degradation in Light Water Reactors, K. L. Murty, Ed. Woodhead Publishing, 2013, pp. 246-283.

[2] A. Strasser, F. Garzarolli, P. Rudling, and C. Patterson, 'Processes going on in Nonfailed Rod during Accident Conditions (LOCA and RIA) Volume II', 2010.

[3] S. Leistikow, G. Schanz, H. Berg, and A. Aly, 'Comprehensive presentation of extended Zircaloy-4 steam oxidation results (600-1600 deg. C)', 1983.

[4] J. H. Baek and Y. H. Jeong, 'Breakaway phenomenon of Zr-based alloys during a high-temperature oxidation', J. Nucl. Mater., vol. 372, no. 2, pp. 152-159, 2008, doi: https://doi.org/10.1016/j.jnucmat.2007.02.011.

[5] Y. Yan, T. Burtseva, and M. Billone, 'High-temperature steam-oxidation behavior of Zr-1Nb cladding alloy E110', J. Nucl. Mater., vol. 393, no. 3, pp. 433-448, 2009.

[6] H.-G. Kim, I.-H. Kim, B.-K. Choi, and J.-Y. Park, 'A study of the breakaway oxidation behavior of zirconium cladding materials', J. Nucl. Mater., vol. 418, no. 1, pp. 186-197, 2011, doi: https://doi.org/10.1016/j.jnucmat.2011.06.039.

[7] M. Billone, Y. Yan, T. Burtseva, R. Daum, and others, 'Cladding embrittlement during postulated loss-of-coolant accidents.', Argonne National Laboratory (ANL), 2008.

[8] M. Steinbrück, N. Vér, and M. Grosse, 'Oxidation of Advanced Zirconium Cladding Alloys in Steam at Temperatures in the Range of $600-1200{ }^{\circ} C^{\prime}$, Oxid. Met., vol. 76, no. 3, pp. $215-232$, Oct. 2011, doi: 10.1007/s11085-011-9249-3.

[9] L. Portier, T. Bredel, J. Brachet, V. Maillot, J. Mardon, and A. Lesbros, 'Influence of Long Service Exposures on the Thermal-Mechanical Behavior of Zy-4 and M5 ${ }^{\mathrm{TM}}$ Alloys in LOCA Conditions', in Zirconium in the Nuclear Industry: Fourteenth International Symposium, 2005.

[10] M. Le Saux, J. Brachet, V. Vandenberghe, D. Gilbon, J. Mardon, and B. Sebbari, 'Influence of pretransient oxide on LOCA high temperature steam oxidation and post-quench mechanical properties of Zircaloy-4 and $\mathrm{M}^{\mathrm{TM}}{ }^{\mathrm{M}}$ cladding', in Water Reactor Fuel Performance Meeting, paper T3-040, 2011.

[11] J.-C. Brachet et al., 'Influence of hydrogen content on the $\alpha / \beta$ phase transformation temperatures and on the thermal-mechanical behavior of $\mathrm{Zy}-4, \mathrm{M} 4$ ( $\mathrm{ZrSnFeV})$, and $\mathrm{M} 5^{\mathrm{TM}}(\mathrm{ZrNbO})$ alloys during the first phase of LOCA transient', in Zirconium in the Nuclear Industry: Thirteenth International Symposium, 2002.

[12] T. Ahmed and L. Keys, 'The breakaway oxidation of zirconium and its alloys a review', J. Common Met., vol. 39, no. 1, pp. 99-107, 1975.

[13] J. Böhmert, M. Dietrich, and J. Linek, 'Comparative studies on high-temperature corrosion of ZrNb1 and Zircaloy-4', Nucl. Eng. Des., vol. 147, no. 1, pp. 53-62, 1994.

[14] K. Park, K. Kim, T. Yoo, and K. Kim, 'Pressure effects on high temperature steam oxidation of zircaloy-4', Met. Mater. Int., vol. 7, no. 4, pp. 367-373, Jul. 2001, doi: 10.1007/BF03186081.

[15] J. H. Baek, K. B. Park, and Y. H. Jeong, 'Oxidation kinetics of Zircaloy-4 and Zr-1Nb-1Sn-0.1Fe at temperatures of $700-1200^{\circ} \mathrm{C}^{\prime}$, J. Nucl. Mater., vol. 335, no. 3, pp. 443-456, 2004, doi: https://doi.org/10.1016/j.jnucmat.2004.08.007.

[16] H. H. Kim, J. H. Kim, J. Y. Moon, H. S. Lee, J. J. Kim, and Y. S. Chai, 'High-temperature oxidation behavior of Zircaloy-4 and Zirlo in steam ambient', J. Mater. Sci. Technol., vol. 26, no. 9, pp. 827832, 2010.

[17] H. E. Kadiri et al., 'Transformations and cracks in zirconia films leading to breakaway oxidation of Zircaloy', Acta Mater., vol. 61, no. 11, pp. 3923-3935, 2013, doi: https://doi.org/10.1016/j.actamat.2013.02.052.

[18] D. J. Park, J. Y. Park, Y. H. Jeong, and J. Y. Lee, 'Microstructural characterization of $\mathrm{ZrO}_{2}$ layers formed during the transition to breakaway oxidation', J. Nucl. Mater., vol. 399, no. 2, pp. 208211, 2010, doi: https://doi.org/10.1016/j.jnucmat.2010.01.021. 
[19] L. Keys, G. Beranger, B. De Gélas, and P. Lacombe, 'Etude micrographique du processus de desquamation ("break-away") au cours de l'oxydation du zirconium', J. Common Met., vol. 14, no. 2, pp. 181-200, 1968.

[20] E. H. Kisi, C. J. Howard, and R. J. Hill, 'Crystal structure of orthorhombic zirconia in partially stabilized zirconia', J. Am. Ceram. Soc., vol. 72, no. 9, pp. 1757-1760, 1989.

[21] H.-I. Yoo, B.-J. Koo, J.-O. Hong, I.-S. Hwang, and Y.-H. Jeong, 'A working hypothesis on oxidation kinetics of Zircaloy', J. Nucl. Mater., vol. 299, no. 3, pp. 235-241, 2001.

[22] H. Okamoto, 'O-Zr (Oxygen-Zirconium)', J. Phase Equilibria Diffus., vol. 28, no. 5, pp. 498-498, 2007.

[23] J. Godlewski, J. Gros, M. Lambertin, J. Wadier, and H. Weidinger, 'Raman spectroscopy study of the tetragonal-to-monoclinic transition in zirconium oxide scales and determination of overall oxygen diffusion by nuclear microanalysis of $\mathrm{O}^{18}$, in Zirconium in the Nuclear Industry: Ninth International Symposium, 1991.

[24] J. Godlewski, 'How the tetragonal zirconia is stabilized in the oxide scale that is formed on a zirconium alloy corroded at $400{ }^{\circ} \mathrm{C}$ in steam', in Zirconium in the nuclear industry: Tenth international symposium, 1994.

[25] R. C. Garvie, 'The occurrence of metastable tetragonal zirconia as a crystallite size effect', J. Phys. Chem., vol. 69, no. 4, pp. 1238-1243, 1965.

[26] G. Baldinozzi, D. Simeone, D. Gosset, and M. Dutheil, 'Neutron diffraction study of the sizeinduced tetragonal to monoclinic phase transition in zirconia nanocrystals', Phys. Rev. Lett., vol. 90, no. 21, p. 216103, 2003.

[27] J. Godlewski, P. Bouvier, G. Lucazeau, and L. Fayette, 'Stress distribution measured by Raman spectroscopy in zirconia films formed by oxidation of Zr-based alloys', in Zirconium in the Nuclear Industry: Twelfth International Symposium, 2000.

[28] R. Guillou et al., 'In-situ time-resolved study of structural evolutions in a zirconium alloy during high temperature oxidation and cooling', Mater. Charact., p. 109971, 2019.

[29] L. Yegorova, K. Lioutov, V. Smirnov, A. Goryachev, and V. Chesanov, 'LOCA Behavior of E110 Alloy', in Nuclear Safety Research Conference, Washington, DC, 2003.

[30] H. K. Yueh et al., 'Loss of Coolant Accident Testing Round Robin', Oak Ridge National Lab.(ORNL), Oak Ridge, TN (United States), 2013.

[31] D. Gosset, M. Le Saux, D. Simeone, and D. Gilbon, 'New insights in structural characterization of zirconium alloys oxidation at high temperature', J. Nucl. Mater., vol. 429, no. 1, pp. 19-24, 2012.

[32] D. Gosset and M. L. Saux, 'In-situ X-ray diffraction analysis of zirconia layer formed on zirconium alloys oxidized at high temperature', J. Nucl. Mater., vol. 458, no. Supplement C, pp. 245-252, 2015, doi: https://doi.org/10.1016/j.jnucmat.2014.12.067.

[33] S. Leistikow and G. Schanz, 'Oxidation kinetics and related phenomena of zircaloy-4 fuel cladding exposed to high temperature steam and hydrogen-steam mixtures under PWR accident conditions', Nucl. Eng. Des., vol. 103, no. 1, pp. 65-84, 1987, doi: https://doi.org/10.1016/00295493(87)90286-X.

[34] M. Amaya and F. Nagase, 'The relationship between the amount of oxidation and activation energy on the steam oxidation reaction of Zircaloy-4 cladding', J. Nucl. Mater., vol. 440, no. 1-3, pp. 457-466, Sep. 2013, doi: 10.1016/j.jnucmat.2013.01.292.

[35] T. Furuta and S. Kawasaki, 'Reaction behavior of zircaloy-4 in steam-hydrogen mixtures at high temperature', J. Nucl. Mater., vol. 105, no. 2, pp. 119-131, 1982, doi: https://doi.org/10.1016/0022-3115(82)90366-X.

[36] G. Schanz, S. Leistikow, and H. Uetsuka, 'Investigations of zircaloy-4 cladding oxidation under steam starvation and hydrogen blanketing conditions', 1984.

[37] F. Nagase, T. Otomo, and H. Uetsuka, 'Oxidation kinetics of low-Sn Zircaloy-4 at the temperature range from 773 to 1,573 K', J. Nucl. Sci. Technol., vol. 40, no. 4, pp. 213-219, 2003.

[38] M. Grosse, 'Comparison of the High-Temperature Steam Oxidation Kinetics of Advanced Cladding Materials', Nucl. Technol., vol. 170, no. 1, pp. 272-279, Apr. 2010, doi: 10.13182/NT10-A9464. 
[39] I. Idarraga, M. Mermoux, C. Duriez, A. Crisci, and J. Mardon, 'Raman investigation of pre-and post-breakaway oxide scales formed on Zircaloy-4 and $\mathrm{M} 5^{\circledR}$ in air at high temperature', J. Nucl. Mater., vol. 421, no. 1, pp. 160-171, 2012.

[40] D. Simeone, G. Baldinozzi, D. Gosset, M. Dutheil, A. Bulou, and T. Hansen, 'Monoclinic to tetragonal semireconstructive phase transition of zirconia', Phys. Rev. B, vol. 67, no. 6, p. 064111, 2003.

[41] R. C. Garvie and P. S. Nicholson, 'Phase Analysis in Zirconia Systems', J. Am. Ceram. Soc., vol. 55, pp. 303-305, 2006, doi: 10.1111/j.1151-2916.1972.tb11290.x.

[42] M. Parise, O. Sicardy, and G. Cailletaud, 'Modelling of the mechanical behavior of the metaloxide system during Zr alloy oxidation', J. Nucl. Mater., vol. 256, no. 1, pp. 35-46, 1998.

[43] S. Leistikow and S. Schanz, 'The oxidation behavior of Zircaloy-4 in steam between 600 and $1600^{\circ}$ C', Mater. Corros., vol. 36, no. 3, pp. 105-116, 1985.

[44] M. Steinbrueck, 'Oxidation of zirconium alloys in oxygen at high temperatures up to $1600 \mathrm{C}^{\text {', }}$ Oxid. Met., vol. 70, no. 5-6, pp. 317-329, 2008.

[45] M. Pijolat and M. Soustelle, 'Experimental tests to validate the rate-limiting step assumption used in the kinetic analysis of solid-state reactions', Thermochim. Acta, vol. 478, no. 1-2, pp. 34-40, 2008. 